АРШИН Константин Валерьевич - старший научный сотрудник департамента политологии факультета социальных наук и массовых коммуникаций Финансового университета при Правительстве РФ (125993, Россия, г. Москва, ГСП-3, Ленинградский пр-кт, 49; Kosta-10@yandex.ru)

\title{
МОДЕЛИРОВАНИЕ ПРОЦЕССОВ АДАПТАЦИИ/ИНТЕГРАЦИИ МИГРАНТОВ: МЕТОДОЛОГИЧЕСКИЙ АСПЕКТ
}

\begin{abstract}
Аннотация. В свете растущих миграционных потоков вопрос адаптации/интеграции мигрантов в принимающий социум становится одним из наиболее актуальных. Государства-реципиенты по-разному решают его. В ряде стран во главу угла ставится необходимость интеграции мигрантов в принимающее сообщество путем индивидуальной работы с мигрантами (Германия), другие страны, наоборот, делают ставку на работу с объединениями мигрантов - диаспорами (Канада). В данной статье представлена методологическая попытка создания модели адаптации/интеграции мигрантов на основе выделения основных акторов указанной работы, описания их деятельности, определения тех трудностей, с которыми они могут столкнуться.
\end{abstract}

Ключевые слова: модель, миграция, адаптация, интеграция, диаспора, община, государственные органы

B рамках политической науки моделирование используется для построения объекта, необходимого для проведения мысленного эксперимента. Реализация последнего в рамках социальных наук, к которым относится и политическая наука, ограничена тем, что, во-первых, объектом эксперимента выступают люди, обладающие своими интересами, а во-вторых, научный эксперимент требует обеспечения возможности постоянного воспроизведения. Для социальных объектов, которые находятся в ситуации постоянной эволюции под воздействием интересов и мнений людей, выполнение указанных условий практически невозможно. Как следствие, используются модели. При формировании таких моделей необходимо соблюдение таких условий, как:

- простота (модель всегда проще объекта, который она воспроизводит);

- целостность (в заданной предметной плоскости модель должна отражать качественную определенность объекта);

- полнота (при построении модели должны быть учтены все существенные элементы модели и параметры их взаимосвязи);

- взаимодействие со средой (модель должна учитывать все существенные для ее функционирования связи со средой);

- системность (при создании модели необходимо следовать системному подходу);

- единый понятийный аппарат (при описании элементов модели и законов, которым они подчиняются, необходимо использовать единый концептуальный понятийный ряд).

Соответственно, выделяют четыре основных типа моделей:

- описательный (в данном случае модель лишь описывает сложившееся состояние политической ситуации или политического института);

- сценарный (описание сценариев развития политической ситуации или политического института на основе существующих обстоятельств);

- прогностический (формирование прогнозов развития политической ситуации или института);

- проблемный (выявление на основе модели несоответствия между желае- 
мым состоянием политической ситуации или политического института и его актуальным состоянием) [Акопов, Унтилрова 2013; Шабров 2002].

В рамках данной статьи будет осуществлена попытка представить описательную модель адаптации/интеграции мигрантов в Российской Федерации.

Прежде всего, полагаем необходимым при создании модели представить основные субъекты, а также условия их взаимодействия.

Согласно российской адаптационной модели, центральным государственным органом, в полном объеме занимающимся всем спектром вопросов адаптации иностранных граждан и лиц без гражданства, является Федеральное агентство по делам национальностей (ФАДН России), которое, согласно пп. «а» п. 2 указа Президента РФ «О Федеральном агентстве по делам национальностей»1, осуществляет выработку и реализацию государственной политики в сфере социальной и культурной адаптации иностранных граждан в РФ и нормативное правовое регулирование в данной области отношений. Характерно, что ФАДН никоим образом не относится к блоку правоохранительных органов, является абсолютно самостоятельным и обособленным с точки зрения предмета ведения федеральным органом исполнительной власти, руководство которым, согласно п. 3 того же президентского указа ${ }^{2}$, осуществляется непосредственно правительством РФ.

Помимо ФАДН, к реализации мер по адаптации/интеграции мигрантов подключен еще целый ряд федеральных структур, а именно Министерство труда и социального развития Российской Федерации, Рособрнадзор, Минэкономразвития России, МИД России и некоторые другие. К числу компетентных органов по вопросам адаптации, безусловно, следует отнести и МВД России в лице Главного управления по вопросам миграции как органа, уполномоченного в сфере миграции в широком смысле этого слова и реализующего в этой сфере властные полномочия, в т.ч. и социально-экономической и гуманитарной направленности (например, реализация властных полномочий по вопросам трудоустройства иностранных граждан, в области убежища и беженцев и т.п.). В то же время следует отметить, что прямого указания на осуществление культурной и социальной адаптации иностранных граждан как самостоятельной функции статусный документ МВД России не предусматривает, что, однако, ни в коем случае не исключает это ведомство из числа субъектов реализации государственной политики по вопросам адаптации мигрантов. Аналогичным образом и положения о некоторых других государственных органах (например, Минэкономразвития России и Минтруда России) также не предусматривают прямое указание на компетенцию по данному вопросу, но сам по себе многогранный характер деятельности по адаптации иностранных граждан (экономические, торговые, финансовые аспекты, предпринимательство, инвестиции и т.д.) делает участие всех этих органов абсолютно необходимым фактором эффективности и результативности адаптационных мероприятий.

Не менее важную роль в рамках реализации мер по адаптации/интеграции мигрантов играет само принимающее общество. Как справедливо указывает отечественный исследователь В.И. Мукомель, «в российском дискурсе роль принимающего общества в процессе интеграции мигрантов рассматривается почти исключительно в контексте проблем межэтнической напряженности и межэтнических отношений» [Мукомель 2016: 425]. Как следствие, недостаточ-

1 Указ Президента РФ от 31.03.2015 № 168 «О Федеральном агентстве по делам национальностей». Доступ: http://www.consultant.ru/document/cons_doc_LAW_177296/ (проверено 21.07.2020).

2 Там же. 
ное внимание уделяется межличностным отношениям между представителями мигрантских сообществ и коренного населения, а также эффективности функционирования институтов, призванных обеспечить реализацию мер по адаптации и интеграции. И напротив, излишне высокое внимание уделяется межгрупповым взаимодействиям. Как следствие, становится сложно определить причины снижения напряженности между коренным населением и мигрантами, исчезновения, сохранения и возрождения тех или иных претензий и фобий. В качестве примера можно привести динамику снижения ксенофобских и антииммигрантских настроений в России в течение 2013-2019 гг. Так, если в октябре «2013 г. на фоне прошедшей выборной кампании мэра Москвы, событий на Матвеевском рынке и в Бирюлево, $81 \%$ опрошенных выступали за ограничение проживания на территории России представителей тех или иных национальностей, то в августе 2015 г. такую позицию поддерживали $65 \%$ респондентов» [Пипия 2015]. Однако опросы, проведенные в 2019 г., демонстрируют, что доля выступающих за ограничение трудовой миграции снова выросла, достигнув $72 \%$. Одновременно увеличилось число тех, кто выступает за ограничение проживания в России выходцев из Средней Азии - до 32\%, уроженцев Кавказа - до $31 \%$, украинцев - до 18\% [Мухаметшина 2019].

Однако инструмент формирования мигрантофобии установить достаточно просто - это средства массовой информации. Исследование, проведенное В.И. Мукомелем, демонстрирует прямую связь между числом публикаций о мигрантах и уровнем мигрантофобии. Так, если в 2013 г. по данным системы «Медиалогия» было 155,8 тыс. публикаций (уровень мигрантофобии - 81\%), посвященных мигрантам, то в 2015 г. - 56,8 тыс. сообщений (уровень мигрантофобии - 65\%). При этом указанные публикации включали в себя как информацию телевизионных каналов, радио и бумажных газет, так и интернет-СМИ [Мукомель 2016].

Важную роль играет также поведение самих мигрантов, их желание адаптироваться к условиям принимающего сообщества и интегрироваться в него. Принципиальное значение в данном случае имеет знание мигрантом языка страны пребывания. По состоянию на 2011 г. около 15-20\% мигрантов, прибывающих в РФ, не знали русского языка, $30 \%$ жаловались на нехватку знания языка для бытового общения, $20 \%$ - на трудности при общении на работе, а 50\% мигрантов не обладали достаточными знаниями языка для заполнения официальных документов [Леденева 2013].

В подобных условиях большую роль играют организации мигрантов, которые предоставляют прибывшим помощь в первичной адаптации к условиям принимающего сообщества и обеспечивают сопровождение мигранта в течение прохождения им адаптационных и интеграционных процедур. Указанные организации могут быть двух типов - диаспоры и общины. Формально между ними практически отсутствуют различия. И те и другие по сути дела защищают своих членов от последствий социальной дезорганизации, которая обязательно наступает в случае погружения человека в иноязычную и инокультурную среду, а именно предоставляют доступ к жилью и работе, формируют персональные контакты, поддерживают статус, организуют свободное время. Однако делают они это по-разному и с разной целью.

Диаспоры, по сути дела, выступая своего рода посредником между мигрантом, государственными органами и общественными организациями, консервируют различия между мигрантами и коренным населением, создавая искусственное сообщество, в котором поддерживаются нормативные образцы, поведенческие коды и статусная система государства исхода, и тем самым препятствуют адаптации и интеграции мигрантов [Коллиер 2016]. Последствием этого может 
стать феномен сукцессии, под которой понимается замещение одной гомогенной группы на определенной территории (коренного населения) другой гомогенной группой (мигрантами), т.е. формирование этнического анклава.

Общины, как правило, имея официальный статус общественных организаций, наоборот, реализуют меры, направленные на приобретение мигрантами знаний и навыков проживания в государствах-реципиентах, одновременно поддерживая у мигрантов их национальную и культурную идентичность. Иными словами, общины предоставляют мигрантам набор «последовательных и связных определений ситуаций, а также соответствующих этим определениям правил поведения» [Сафонова 2012]. Диаспоры этого не делают. Вместе с тем нельзя воспринимать деятельность диаспор как исключительно негативную. При отсутствии диаспор мигранты оказываются более подверженными социальным болезням, таким как преступность, алкоголизм, наркомания, деклассирование.

Таким образом, очевидно, что в целях обеспечения эффективности процессов адаптации и интеграции мигрантов деятельность диаспор должна быть ограничена и наоборот, деятельность общин должна поощряться. В рамках правового демократического государства это возможно делать в рамках установления правовых процедур, основанных на соответствующей нормативной правовой базе.

В России процесс оформления нормативной правовой основы деятельности по адаптации иностранных граждан еще не завершен, хотя многие базовые параметры уже нашли свое отражение в законодательстве и реализуются на практике. Речь прежде всего идет о таких ключевых для адаптации иммигрантов критериях, как уверенное владение языком государства пребывания, знание его правовых основ и истории. Все эти моменты достаточно детально проработаны и закреплены в федеральном законодательстве - например, в федеральных законах «О правовом положении иностранных граждан в Российской Федерации», «О гражданстве Российской Федерации», иных законах, целом ряде подзаконных актов. При этом отсутствует базовый специальный законодательный акт, комплексно регулирующий вопросы адаптации (интеграции).

На протяжении последних 5 лет как минимум дважды предпринимались попытки создания соответствующего закона, однако они не увенчались успехом. Так, в 2014 г. ФМС России в рамках реализации предыдущей редакции Концепции государственной миграционной политики разработала проект федерального закона «О социальной и культурной адаптации и интеграции иностранных граждан в Российской Федерации», однако после общественных обсуждений, состоявшихся летом того же года, работа над ним была фактически прекращена. Несколько позже проект аналогичного содержания готовился ФАДН России во исполнение соответствующего поручения президента РФ. Однако и в данном случае работа была приостановлена.

В законодательстве РФ можно четко выделить некоторые приоритетные категории иностранных граждан в плане реализации в отношении их адаптационной деятельности с режимом наибольшего благоприятствования по сравнению с иными категориями мигрантов. Так, согласно пп. 6 п. 5 и п. 6 ст. 15.1 федерального закона «О правовом положении иностранных граждан в Российской Федерации» («Подтверждение иностранными гражданами владения русским языком, знания истории России и основ законодательства Российской Федерации») от подтверждения владения русским языком, знания истории России и основ законодательства РФ полностью освобождены высококвалифицированные специалисты и члены их семей, что, безусловно, свидетельствует об их особом, привилегированном положении. При этом именно знание 
языка страны пребывания, ее истории и общественного устройства образуют базис для интеграции/адаптации иностранных граждан. С одной стороны, это создает для высококвалифицированных мигрантов особые условия, упрощающие их полноценное долгосрочное обустройство в стране пребывания, однако, с другой стороны, препятствует формированию крепких связей со страной пребывания. Как следствие, формируются «сообщества экспатов», в значительной степени напоминающие диаспоры и препятствующие укоренению высококвалифицированных специалистов в стране пребывания.

В свою очередь, деятельность общин как национальных объединений регулируется тремя федеральными законами: федеральными законами от 19 мая 1995 г. № 82-Ф3 «Об общественных объединениях», от 17 июня 1996 г. № 74-Ф3 «О национально-культурной автономии», от 12 января 1996 г. № 7-Ф3 «О некоммерческих организациях». Указанные законы устанавливают правила создания, деятельности и ликвидации национальных объединений. Важной правовой новацией стало внесение деятельности по адаптации и интеграции мигрантов в список видов деятельности, реализация которых может позволить национальному объединению, созданному в форме некоммерческой организации, претендовать на статус социально ориентированной некоммерческой организации. Получение подобного статуса предоставляет СО НКО право на приоритетное получение поддержки со стороны органов государственной и муниципальной власти, а также владения государственным имуществом, бесплатного информационного обеспечения деятельности в государственных и муниципальных СМИ, бесплатного и приоритетного прохождения сотрудниками и добровольцами СО НКО курсов повышения квалификации и обучающих мероприятий.

Изложенное выше позволяет дать краткое описание политико-правовой модели адаптации/интеграции мигрантов. Указанная модель представляет собой систему, у которой, как и у любой системы, существует вход и выход. Вход этой системы формируют миграционные потоки, которые разделяются между диаспорами и общинами (национальными объединениями). Поскольку диаспоры, как правило, носят неформальный характер, они оказываются вне нормативного правового поля. В свою очередь, общины (национальные объединения), наоборот, вынуждены действовать в рамках указанного поля, в силу чего должны подчиняться определенным требованиям, но и получают определенную поддержку. В свою очередь, органы государственной и муниципальной власти предъявляют свои требования к общинам, предоставляют им поддержку, но и сами вынуждены реагировать на требования со стороны общин (национальных объединений). Задача общин на данном этапе состоит в регулировании потоков мигрантов, проходящих процедуры адаптации и интеграции, с целью не допустить перегрузки системы. На органы государственной и муниципальной власти, а также общины оказывают влияние СМИ. СМИ также взаимодействуют со средой, которую, в свою очередь, формирует коренное население. В рамках указанного взаимодействия создается общественное мнение, которое опосредованно оказывает влияние на все составные части системы адаптации и интеграции мигрантов через предъявление требований к органам государственной и муниципальной власти, правоохранительным органам, общинам. Выход системы формируют мигранты, прошедшие процедуры адаптации и интеграции.

Если число мигрантов, прошедших процедуры адаптации и интеграции, удовлетворяет запросам окружающей среды, то поддержка политического курса усиливается, снижается степень мигрантофобии и ксенофобии. В противном случае показатели мигрантофобии растут, и система приходит в упадок. 
Те мигранты, которые не смогли успешно завершить процедуры адаптации и интеграции, пополняют ряды диаспоры (в лучшем случае) либо превращаются в деклассированные элементы и пополняют ряды преступных сообществ. Контроль над диаспорами осуществляют правоохранительные органы, они же реализуют меры по борьбе с преступными сообществами и деклассированными элементами.

Следует отметить, что часть мигрантов может пройти процедуры адаптации и интеграции, минуя фазу вхождения в общину (национальное объединение). Таких мигрантов может быть достаточно много, однако в рамках данной модели ими следует пренебречь.

Схематичное изображение данной системы приведено на рис. 1.

Представленное описание модели адаптации/интеграции мигрантов позволяет сделать следующие выводы.

1. Субъектами процессов адаптации и интеграции мигрантов выступают диаспоры, общины (национальные объединения), коренные жители, органы государственной и муниципальной власти, средства массовой информации.

2. Успех процесса адаптации и интеграции мигрантов оценивается не числом мигрантов, прошедших процедуру адаптации и/или интеграции, а оценкой успешности ее прохождения общественным мнением.

3. Само общественное мнение находится под достаточно серьезным воздействием средств массовой информации, которые не только отражают его, но и формируют. Вследствие этого СМИ могут исказить общественное мнение как в сторону позитивной, так негативной оценки проводимой работы по адаптации/ интеграции мигрантов.

4. Серьезную опасность для процессов адаптации/интеграции мигрантов представляют неформальные объединения в видее диаспор, которые «консервируют» нахождение мигрантов в искусственной социальной среде, похожей на социальную среду стран исхода, выступая посредником между мигрантом и коренным населением. Тем самым у мигранта формируется социальная установка об отсутствии необходимости прохождения процедуры адаптации/интеграции в социум страны-реципиента.

Статья подготовлена по результатам исследований, выполненных за счет бюджетныхсредств погосударственному заданию Финуниверситету.

\section{Список литературы}

Акопов А.К., Унтилрова И.Л. 2013. Политические модели мирового порядка. - Научно-технические ведомости СПбГПУ. Гуманитарные и общественные науки. № 2. С. 34-37.

Коллиер П. 2016. Исход. Как миграция меняет нашу жсизнь. М.: Изд-во Института им. Е.Т. Гайдара. 381 с.

Леденева В.Ю. 2013. Адаптационные ресурсы социальной интеграции трудящихся мигрантов в принимающей среде. - Вестник ГУУ. № 8. С. 218-222.

Мукомель В.И. 2016. Адаптация и интеграция мигрантов: методологические подходы к оценке результативности и роль принимающего общества. - Россия реформирующаяся: ежегодник (сборник научных статей). М.: Новый хронограф. Вып. 14. С. 411-467.

Мухаметшина Е. 2019. Ксенофобские настроения в России растут второй год подряд. - Левада-Центр. Доступ: https://www.levada.ru/2019/09/18/ksenofobskienastroeniya-v-rossii-rastut-vtoroj-god-podryad/ (проверено 20.07.2020).

Пипия К. 2015. Ксенофобия и национализм. - Левада-Центр. Пресс-выпуск. 


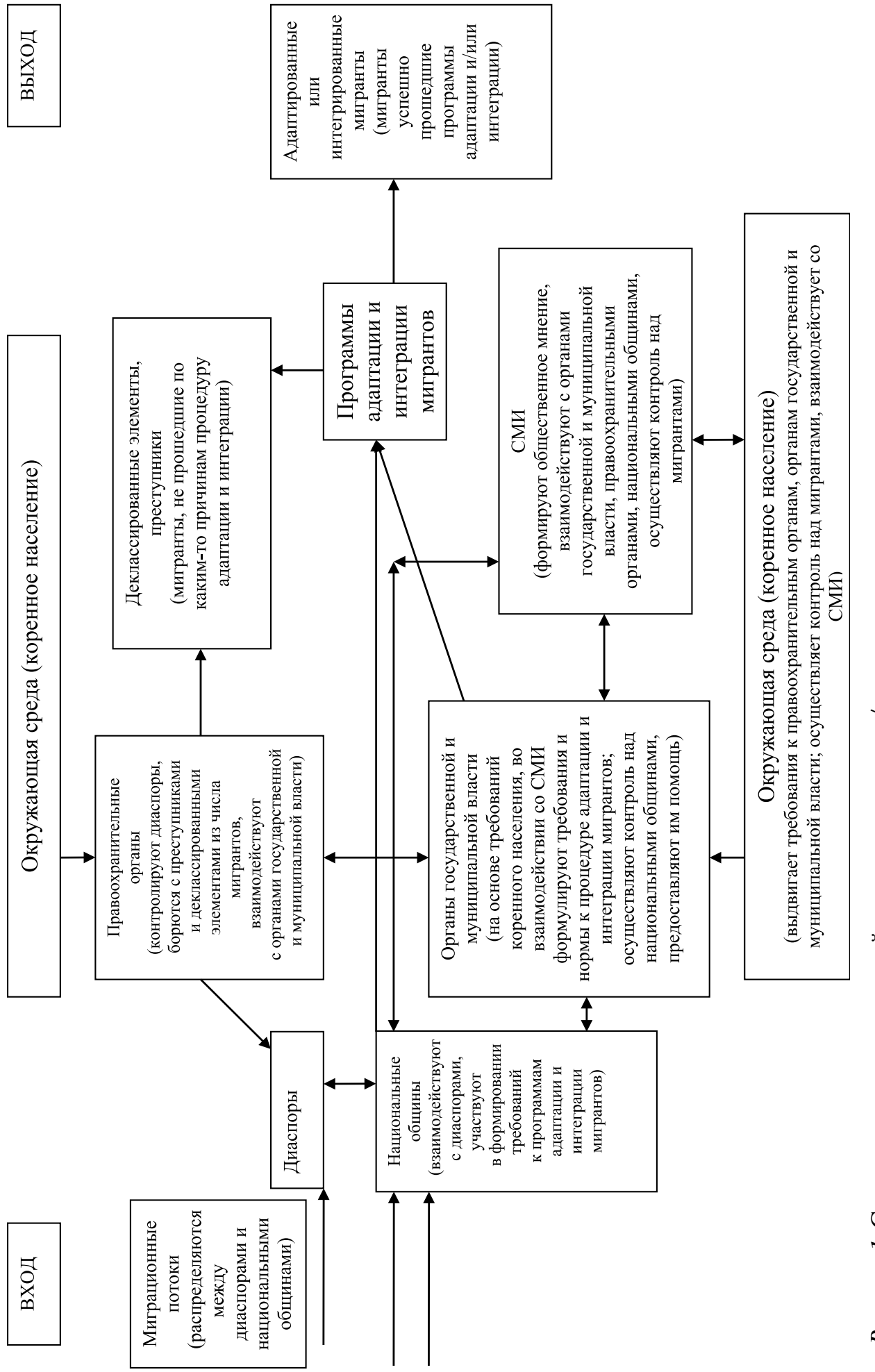

| 
25.08. Доступ: http://www.levada.ru/25-08-2015/ksenofobiya-i-natsionalizm (проверено 20.07.2020).

Сафонова М.А. 2012. Концепции функционирования мигрантских сообществ в американской социологии. Доступ: http://ecsocman.hse.ru/ data/2012/09/12/1265233195/Safonova.pdf (проверено 20.07.2020).

Шабров О.Ф. 2002. Моделирование политической реальности. - Политология: учебник. М.: Изд-во РАГС. С. 448-461.

ARSHIN Konstantin Valerievich, Senior Researcher of the Department of Political Science, Faculty of Social Sciences and Mass Communications, Financial University under the Government of the Russian Federation (49 Leningradsky Ave, GSP-3, Moscow, Russia, 125993; Kosta-10@yandex.ru)

\title{
TO THE ISSUE OF THE MODEL OF MIGRANT ADAPTATION/INTEGRATION: METHODOLOGICAL ASPECT
}

Abstract. In the light of growing migration flows, the issue of migrant adaptation/integration into the host society is becoming one of the most relevant. Recipient states deal with it differently. In a number of countries, they give a priority to the need to integrate migrants into the host community through individual work with them (Germany), while other countries, on the contrary, rely on work with migrant associations - diasporas (Canada). This article presents a methodological attempt to create a model of migrant adaptation/integration, based on highlighting the main actors of this work, describing their activities, identifying the difficulties that they may encounter.

Keywords: model, migration, adaptation, integration, diaspora, community, government bodies

КУЧЕРОВ Михаил Юрьевич - студент факультета управления и политики Московского государственного института международных отношений (университет) МИД РФ (119454, Россия, г. Москва, пр-кт Вернадского, 76; kисhеrov.m.уи@уапdех.ru)

\section{МИГРАЦИОННЫЙ КРИЗИС В ГЕРМАНИИ: НАГРУЗКА ИЛИ ИНВЕСТИЦИИ В БУДУЩЕЕ?}

\begin{abstract}
Аннотация. Статья посвящена миграционному вопросу, который в современном российском дискурсе приобрел устойчивую негативную коннотацию, особенно при восприятии данной тематики в отношении развитых государств Западной Европы. Принято считать, что усилившиеся за последние годы миграционные потоки наносят ощутимый вред экономическому и политическому развитию европейских стран. Целью данной статьи является детальное рассмотрение тех возможностей, которые миллионы прибывающих в Западную Европу мигрантов представляют для увеличения темпов экономического роста, нормализации демографической ситуации и стабильного развития европейских государств, в частности ФРГ, в ближайшие десятилетия.
\end{abstract}

Ключевые слова: миграционный кризис, интеграция, беженцы, мигранты, Германия

$\Gamma$ ермания стала страной иммиграции в 60-е гг. XX в., когда бурный экономический рост и восстановление страны после разрушительной войны потребовали задействования новых рабочих рук. Именно в этот период прави- 